\title{
Uranil iyonlarının sulu çözeltilerden amidoksimatlı poli[N-(3,4- disiyanofenil) akrilamid] üzerine adsorpsiyonu
}

\author{
Çiğdem Öter ${ }^{*}$, Özlem Selçuk Zorer ${ }^{2}$ \\ 1 Yüzüncü Y1l Üniversitesi, Fen Fakültesi, Van, Türkiye, (ORCID: 0000-0002-8262-4882) \\ 2 Yüzüncü Y1l Üniversitesi, Fen Fakültesi, Van, Türkiye, (ORCID: 0000-0002-6486-8365) \\ (İlk Geliş Tarihi 26 Ağustos 2019 ve Kabul Tarihi 1 Ekim 2019)
}

(DOI: 10.31590/ejosat.610868)

ATIF/REFERENCE: Öter, Ç. \& Selçuk Zorer, Ö. (2019). Uranil iyonlarının sulu çözeltilerden amidoksimatlı poli[N-(3,4disiyanofenil) akrilamid] üzerine adsorpsiyonu. Avrupa Bilim ve Teknoloji Dergisi, (17), 131-144.

\section{$\ddot{O} z$}

Uranyum kirliliği yüksek toksisite ve radyoaktivite içerir. Bu nedenle insan sağlığı ve çevre için ciddi bir tehdit oluşturur. Bu nedenle sulu çözeltilerden uranyumun geri kazanımı için kimyasal çökeltme, iyon değişimi, ters ozmoz ve adsorpsiyon gibi bir dizi teknik geliştirilmiştir. Düşük konsantrasyonlarda, sulu çözeltilerden uranyum gibi uzun ömürlü radyonüklidlerin adsorpsiyon yoluyla ayrılması hem nükleer/radyasyon kimyasında hem de çevre/atık işlem kimyasında önemlidir. Çevre kirliliğinin önlenmesi konusunda ekonomik ve teknik bakımlardan uygulanabilir yöntemlere ihtiyaç duyulması nedeniyle, doğal ve sentetik adsorbanlar üzerinde birçok çalışma yapılmaktadır. Amidoksim grupları içeren polimerlerin ağır metal iyonları içeren kompleksler oluşturma eğiliminde olduğu ve uranyum iyonları içeren komplekslerin de oldukça çok araştırıldığı belirlenmiştir. Bu çalışmada sulu çözeltilerden uranyumun giderilmesi amacıyla amidoksim grupları içeren yeni bir polimer adsorban madde üretilmiştir. N-(3,4-disiyanofenil) akrilamid monomerini sentezlemek için 4-aminoftalonitril ve akriloil klorür kullanıldı ve bu monomer poli [N-(3,4-disiyanofenil) akrilamid]'e polimerize edildi. Son olarak, polimer nitril grupları içeren amidoksimatlanmış forma dönüştürüldü. Monomer, polimer ve amidoksimatlanmış formunun yapısı, FT-IR spektroskopisi ve termal analiz yöntemleri ile karakterize edildi. Temas süresi, $\mathrm{pH}$, ilk konsantrasyon ve amidoksimatlı polimer tarafindan $\mathrm{U}(\mathrm{VI})$ adsorpsiyonu üzerindeki sıcaklık gibi çeşitli deneysel parametrelerin etkisi araştırılmış ve uranyumun sulu çözeltiden adsorpsiyonu için koşullar belirlenmiştir. Kinetik koşullar için, veriler sözde birinci derece, sözde ikinci derece ve partikül içi kinetik modeline uygulandı. Sonuçlar, U(VI) 'nın amidoksimatlanmış polimer üzerindeki adsorpsiyonunun sözde ikinci dereceden kinetik modeline uyduğunu göstermiştir. Denge koşulları için sulu çözeltilerdeki denge verileri Langmuir, Freundlich, Temkin ve Dubinin-Radushkevich gibi farklı sorpsiyon izotermlerine uygulandı. Adsorpsiyon denge verilerinin, U(VI) iyonlarının amidoksimasyonlu polimer tarafından adsorpsiyonunda Langmuir modeline çok uyum gösterdiği ve maksimum adsorpsiyon kapasitesinin $175.4 \mathrm{mg} / \mathrm{g}$ olduğu belirlenmiştir. Termodinamik koşullar için, $\Delta \mathrm{H}^{\circ}, \Delta \mathrm{S}^{\circ}$ ve $\Delta \mathrm{G}^{\circ}$ termodinamik parametreleri hesaplandı ve değerlendirildi. $\Delta \mathrm{G}^{\mathrm{o}}(-2.92 \mathrm{~kJ} / \mathrm{mol})$ negatif değeri, spontanlığı belirtirken, $\Delta \mathrm{H}^{\circ}(15.14 \mathrm{~J} / \mathrm{mol})$ pozitif değeri, amidoksimasyonlu polimer tarafından $\mathrm{U}(\mathrm{VI})$ adsorpsiyonu için adsorpsiyon işleminin endotermik yapısını göstermektedir.

\section{Adsorption of uranyl ions from aqueous solutions onto amidoximated poly[N-(3,4-dicyanophenyl) acrylamide]}

\begin{abstract}
Uranium pollution contains high toxicity and radioactivity. Therefore, it poses a serious threat to human health and the environment. Therefore, a number of techniques have been developed for the recovery of uranium from aqueous solutions, such as chemical precipitation, ion exchange, reverse osmosis and adsorption. At low concentrations, the separation of longevity radionuclides, such as
\end{abstract}

* Sorumlu Yazar: Yüzüncü Y1l Üniversitesi, Fen Fakültesi, Van, Türkiye, ORCID: 0000-0002-8262-4882, cigdem1414@gmail.com 
uranium, from aqueous solutions by adsorption is important in both nuclear/radiation chemistry and environmental/waste treatment chemistry. Due to the need for economic and technical applicable methods for the prevention of environmental pollution, many studies have been carried out on natural and synthetic adsorbents. It has been found that polymers containing amidoxime groups tend to form complexes containing heavy metal ions and complexes containing uranium ions have been investigated quite a lot. In this study, a novel polymer adsorbent containing amidoxime groups was produced to remove uranium from aqueous solutions. 4Aminophthalonitrile and acryloyl chloride were used to synthesize the $\mathrm{N}$ - (3,4-dicyanophenyl) acrylamide monomer, which was polymerized to poly [N- (3,4-dicyanophenyl) acrylamide]. Finally, the polymer was converted to the amidoximatized form containing nitrile groups. The structure of the monomer, polymer and amidoximatized form was characterized by FT-IR spectroscopy and thermal analysis methods. The effect of various experimental parameters such as contact time, pH, initial concentration and temperature on U (VI) adsorption by the amidoximatized polymer was investigated and conditions for adsorption of uranium from aqueous solution were determined. For kinetic conditions, the data were applied to the Pseudo-first order, pseudo-second order, and intra-particle kinetics model. The results showed that the adsorption of U (VI) on the amidoximatized polymer fits the so-called second order kinetic model. For equilibrium conditions, equilibrium data in aqueous solutions were applied to different sorption isotherms such as Langmuir Freundlich, Temkin and Dubinin-Radushkevich. Adsorption equilibrium data were found to be more compatible with Langmuir model in adsorption of $\mathrm{U}$ (VI) ions by amidoximated polymer and maximum adsorption capacity was $175.4 \mathrm{mg} / \mathrm{g}$. For thermodynamic conditions, $\Delta \mathrm{H}^{\mathrm{o}}, \Delta \mathrm{S}^{\mathrm{o}}$ and $\Delta \mathrm{G}^{\mathrm{o}}$ thermodynamic parameters were calculated and evaluated. A negative value of $\Delta G^{\circ}(-2.92 \mathrm{~kJ} / \mathrm{mol})$ indicates spontaneity, while a positive value of $\Delta \mathrm{H}^{\mathrm{o}}(15.14 \mathrm{~J} / \mathrm{mol})$ indicates the endothermic structure of adsorption for $\mathrm{U}(\mathrm{VI})$ adsorption by the amidoximated polymer.

Keywords: Adsorption, Amidoxime, Polymer, Uranium.

\section{Giriş}

Uranyum, nükleer yakıt olarak önemli enerji kaynaklarından biri olarak kabul edilir. Uranyumu doğal deniz suyundan, nehir suyundan ve endüstriyel atık sulardan geri kazanma çabası da oldukça önemlidir. Uranyum gibi başlıca radyoaktif atık ve kirletici kaynakları; elektrik enerjisi üretimi, nükleer yakıtlardan silah üretimi, nükleer silah testleri, yakıtların yeniden işlenmesi ve nükleer kazalardan kaynaklanmaktadır. (Tavengwa ve ark., 2015). Uranyum ve tuzları oldukça toksiktir ve büyük bir sağlık sorunu oluşturur. Böbrek ve kemiklerde ciddi hasara neden olurlar ve beyinde birikirler. Bu nedenle, uranyum ile kirlenmiş atık suları arıtmak için acilen etkili ve ekonomik bir metoda ihtiyaç duyuyor. Bilinen en iyi geleneksel yöntemler membran muamelesi, kimyasal-çökelme, iyon değişimi, özütleme ve adsorpsiyondur. Bununla birlikte, bu yöntemlerin bazıları yüksek işletme maliyetleri, ikincil kirlilik ve ortaya çıkan çamurun bertarafı sorunu olarak bazı olumsuz dezavantajlar göstermiştir. Bu yöntemler arasında adsorpsiyon yöntemi, kolay uygulanabilirlik, düşük maliyet ve yüksek verimlilik gibi avantajlar göstermiştir (Chen ve ark., 2017).

Adsorpsiyon işlemini daha etkin ve az maliyetli bir hale getirmek için birçok araştırmacı ucuz ve yenilenebilir adsorbanlar bulmaya çalışmaktadırlar. Adsorban madde olarak nanomateryaller, aktif karbon, çeşitli polimerler, reçineler, jeller, alüminyum oksit, silikatlar, killer, çeşitli bitki türleri, zeolitler gibi birçok madde kullanılmıştır (Aycan ve Arslan, 2017). Uranil katyonunu kompleksleştiren çeşitli ligand tipleri, ekvator düzleminde uranyum atomuna koordine edilen donör atomları içerir. Amidoksim içeren ligandlar da uranil katyonunu kompleksleştirebilir (Stemper ve ark., 2018). Amidoksime dayalı adsorbanlar, 1960'lardan bu yana yüksek seçiciliği ve uranyumla ilgisi nedeniyle yoğun ilgi görmüştür. Bu adsorbanlar, metal iyonları ile koordinasyon bağı ve stabil yap1 oluşturan elektron bağış gruplarındaki $\left(-\mathrm{NH}_{2}, \mathrm{HNCH}_{3}\right.$ ve $\left.\mathrm{N}\left(\mathrm{CH}_{3}\right)_{2}\right)$ yalnız çift elektronlar sayesinde metal iyonlarını adsorbe eder. Birçok durumda, bu amidoksim-işlevselleştirilmiş malzemeler, akrilonitril grupları $\left(-\mathrm{CH}_{2}-\mathrm{CH}-\mathrm{C} \equiv \mathrm{N}\right)$ katı yapılara sokularak ve daha sonra bu grupları amidoksim gruplarına $\left(-\mathrm{CH}_{2}-\mathrm{CH}-\mathrm{C}\left(\mathrm{NH}_{2}\right)=\mathrm{NOH}\right)$ dönüştürerek sentezlenebilir (Zeng ve ark., 2017).

Uranil'in sulu çözeltilerden, amidoksim-işlevselleştirilmiş iyonik sıvilar (Barber ve ark., 2012), amidoksimler içeren bir gözenekli baskılı polimer (Huang ve ark., 2015) ve amido-oksim modifiye edilmiş mezoporoz silika (Gunathilake ve ark., 2015) ile özütlendiği belirtilmiştir. Kitosanın ve akrilonitrilin çökeltme greft kopolimerizasyonu yoluyla amidoksimsi kitosan aşılanmış poli akrilonitril (CTS-g-PAO) hazırlandığı bir çalışmada, akrilonitril gruplarının hidroksilamin hidroklorür kullanılarak amidoksim gruplarına dönüştürülmesi ile bunların her birinin, hidroksilamin hidroklorür kullanan kombinasyonlarının avantaj sahibi olduğu belirtilmiştir (Xu ve ark., 2015). Yapılan bir çalışmada, elektron ışını kaynaklı akrilonitril ve ikonik asidin polietilen lifi üzerine aşılanması kullanılarak yeni bir amidoksim bazlı polimer adsorban serisi sentezlenmiştir. Sentetik DMSO ile 1sıl işlem görmüş bu adsorbanların deniz suyundan $4.48 \mathrm{~g}$-U/kg-ads kadar yüksek uranyum adsorbe ettiği belirtilmiştir (Das ve ark., 2016). Başka bir çalışmada, PAN/MMT nanokompozitinin interkalasyon polimerizasyonu ile hazırlandığı ve bu adsorbanın uranyum adsorpsiyon kapasitesinin pH 7'de 3,06 mg/g'ye ulaştı̆ğ bildirilmiştir (Shen ve ark, 2012). Simüle edilmiş deniz suyunda uranyum iyonları için pH 7'de $98.425 \mathrm{mg} / \mathrm{g}^{\prime} \mathrm{l}$ k mükemmel seçici adsorpsiyon kapasitesi sergileyen C8A-AO adsorbanının hazırlandığı bir çalışmada, amidoksim grubunun güçlü bir afiniteye sahip olduğu ve nötr veya zayıf alkali bir çözeltide uranil trikarbonat komplekslerini $\left[\mathrm{UO}_{2}\left(\mathrm{CO}_{3}\right)_{3}{ }^{4-}\right]$ etkin bir şekilde şelatlayabildiği görülmüştür (Lu ve ark., 2016).

$\mathrm{Bu}$ çalışmanın amacı, çeşitli deneysel parametrelerin, amidoksimatlı poli[N-(3,4-disiyanofenil) akrilamid] ile uranyum adsorpsiyonu üzerindeki etkisini araştırmak ve adsorpsiyon prosesini denge, kinetik ve termodinamik koşullar açısından değerlendirmektir

\section{Materyal ve Metot}

\subsection{Kimyasallar ve Cihazlar}


Amidoksimatlı polimer sentezinde; monomer sentezi için kullanılan 4-Aminoftalonitril $\left[\mathrm{H}_{2} \mathrm{NC}_{6} \mathrm{H}_{3}-1\right.$,2-( $\left.(\mathrm{CN})_{2}\right]$, trietil amin $\left[\left(\mathrm{C}_{2} \mathrm{H}_{5}\right)_{3} \mathrm{~N}\right]$, akriloil klorür $\left(\mathrm{C}_{3} \mathrm{H}_{3} \mathrm{ClO}\right)$ ve diklor metan $\left(\mathrm{CH}_{2} \mathrm{Cl}_{2}\right)$ ile ikinci aşamada polimerizasyonda başlatıcı olarak kullanılan AIBN [2,2'-azo-bis(izobutironitril)] ve son olarak amidoksimasyon aşamasında kullanılan hidroksilamin hidroklorür $\left(\mathrm{NH}{ }_{2} \mathrm{OH} . \mathrm{HCl}\right)$ reaktifleri ile $\mathrm{UO}_{2}\left(\mathrm{CH}_{3} \mathrm{COO}\right)_{2} .2 \mathrm{H}_{2} \mathrm{O}$ tuzu analitik saflıkta olup Merck firmasından temin edilmiştir.

Deneylerde, WiseStir çoklu mekanik karıştırıcılı 1sıtıcı, NÜVE FN 400 etüv, Thermo Scientific ultra saf su cihazı, 620 Lab pH Meter pH metre, Optizen POP UV spektrofotometre kullanılmıştır. Monomer, polimer ve amidoksimatlı polimer aşamalarının yapısal karakterizasyonu Bio-Rad-Win-IR model FT-IR spektrofotometresi kullanılarak yapılmıştır. Poli[N-(3,4-disiyanofenil) akrilamid] ile amidoksimatlı poli[N-(3,4-disiyanofenil) akrilamid]'in termal kararlılıkları, camsı geçiş sıcaklığı ve erime sıcaklık değerleri, TGA/DSC analizleri Setaram Labsys Evo Gravimetrik Analyzer 1600 Model cihazla belirlendi.

\subsection{Amidoksimatlı poli[N-(3,4-disiyanofenil) akrilamid]'in Sentezlenmesi}

$\mathrm{N}$-(3,4-disiyanofenil) akrilamid monomerin sentezi için; 4-aminoftalonitril (2.5 g), diklor metan (10 mL) ve trietil amin (2.7 mL) karışımı buz banyosunda soğutularak damla damla akriloil klorür (1.5 mL) eklendi ve reaksiyon karışımı 24 saat boyunca oda sıcaklığında karıştırıldı (Şekil 1) ve süre sonunda saf su ile $3 \mathrm{kez}$ ekstrakte edildi, filtre kağıdında süzülen monomer $80^{\circ} \mathrm{C}$ 'de etüvde kurutuldu (Kokosza ve ark., 2013).<smiles>C=CC(=O)Nc1ccc(C#N)c(C#N)c1</smiles>

Şekil 1. N-(3,4-disiyanofenil) akrilamid monomerinin sentez reaksiyonu

Daha sonra bu monomer AIBN başlatıcısı kullanılarak poli[N-(3,4-disiyanofenil) akrilamid] 'e polimerize edildi (Şekil 2).

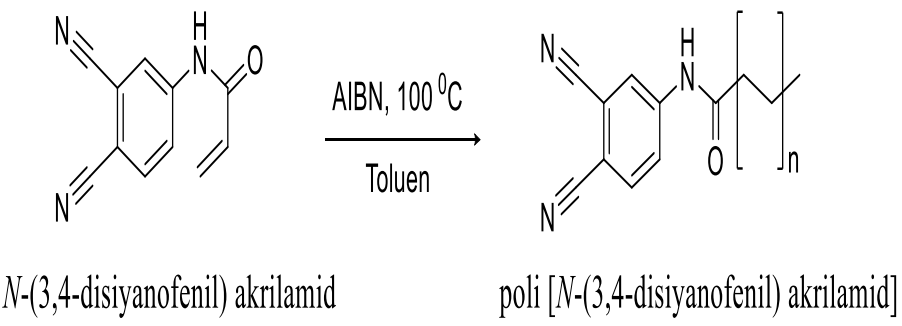

Şekil 2. N-(3,4-disiyanofenil) akrilamid'in polimerleşme reksiyonu

Son olarak, polimer hidroksilamin hidroklorür tuzu ile nitril grupları içeren amidoksimatlanmış forma dönüştürüldü (Pekel ve ark., 2000). Elde edilen amidoksimatlı poli[N-(3,4-disiyanofenil)akrilamid] adsorbanı (Şekil 3) adsorpsiyon işlemlerinde kullanılmak üzere desikatör içerisinde muhafaza edildi.<smiles>CC(NO)C(C)(C)C(=O)Nc1ccc(C#N)c(C#N)c1</smiles><smiles>CCC(C)C(=O)Nc1ccc(/C(N)=N/O)c(/C(N)=N/O)c1</smiles>

poli [N-(3,4-disiyanofenil) akrilamid]

Şekil 3. poli[N-(3,4-disiyanofenil) akrilamid'in amidoksimasyon reaksiyonu

\subsection{Adsorpsiyon Çalışmaları}

Amidoksimatlı poli[N-(3,4-disiyanofenil)]akrilamid adsorbanı üzerine uranyum adsorpsiyonu çalışmaları kesikli yöntem uygulanarak, çoklu manyetik karıştırıcılı 1sıtıcıda gerçekleştirildi. Farklı konsantrasyon ve pH'lardaki uranyum değişen sürelerde farklı sıcaklıklarda adsorban ile temas ettirildi. $\mathrm{pH}$ ayarlamaları için çalışmalarda $\mathrm{CH}_{3} \mathrm{COOH}$ ile $\mathrm{NaOH}$ çözeltileri kullanıldı. 
Adsorplama işlemi sonunda adsorban ile uranyum çözeltileri filtre kağıdı ile süzülerek ayrıldı. Çözelti ortamında kalan uranyum miktarı için ise Arsenazo-III yöntemi spektrofotometrik olarak uygulanmıştır (Wei ve ar., 2007).

Amidoksimatlı poli[N-(3,4-disiyanofenil) akrilamid]'in $\mathrm{t}$ zamanında $\left(\mathrm{q}_{\mathrm{t}}, \mathrm{mg} / \mathrm{g}\right)$ ve dengede $\left(\mathrm{q}_{\mathrm{e}}, \mathrm{mg} / \mathrm{g}\right)$ adsorpsiyon kapasitesi, adsorpsiyon verimi $(\mathrm{A} \%)$, aşağıdaki denklemlerden hesaplandı:

$$
\begin{aligned}
& q_{t}=\frac{\left(C_{0}-C_{t}\right)}{m} \times V \\
& q_{e}=\frac{\left(C_{0}-C_{e}\right)}{m} \times V \\
& A(\%)=\frac{\left(C_{0}-C_{t}\right)}{C_{0}} \times 100
\end{aligned}
$$

Eşitliklerde; $\mathrm{q}_{\mathrm{t}}$ ve $\mathrm{q}_{\mathrm{e}}$ 'nin sırasıyla $\mathrm{t}$ ve dengede adsorpsiyon kapasitesi $\left(\mathrm{mg} \mathrm{g}^{-1}\right)$ olduğu; $\mathrm{C}_{0}, \mathrm{C}_{\mathrm{e}}$ ve $\mathrm{C}_{\mathrm{t}}$, sırasıyla $\mathrm{t}$ zamanında ilk konsantrasyon, uranyum iyonlarının denge konsantrasyonu ( $\left.\mathrm{mg} \mathrm{L}^{-1}\right)$ ve sivı faz konsantrasyonu; $\mathrm{m}$, adsorban (g) 'nin miktarı; çözeltinin hacmi (L) ve A (\%), adsorpsiyon yüzdesidir (Yi ve ark, 2016).

\subsection{Adsorpsiyon Kinetikleri}

Uranyum adsorpsiyon kinetiği, pseudo birinci dereceden ve pseudo ikinci dereceden modellerle aşă̆ıdaki eşitliklere göre araştırıldı.

$$
\begin{aligned}
& \ln \left(q_{e-} q_{t}\right)=\ln q_{e}-\mathrm{k}_{1} . t \\
& \frac{t}{q_{t}}=\frac{1}{k_{2} q_{e}^{2}}+\frac{1}{q_{e}} t
\end{aligned}
$$

Burada; $\mathrm{q}_{\mathrm{t}}$ ve $\mathrm{q}_{\mathrm{e}}$, adsorpsiyon kapasitesi ve dengede adsorbe edilen $\mathrm{U}(\mathrm{VI})$ miktarıdır $\left(\mathrm{mg} \mathrm{g}^{-1}\right), \mathrm{k}_{1}\left(1 \mathrm{dk}^{-1}\right)$ ve $\mathrm{k}_{2}\left(\mathrm{~g} \mathrm{mg}^{-1}\right.$. $\left.\mathrm{dk}^{-1}\right)$, sirasıyla sahte birinci mertebe ve sahte ikinci mertebe modelinin oran sabitidir (Chen ve ark., 2018).

\subsection{Adsorpsiyon İzotermleri}

Denge verileri, en uygun izotermi elde etmek için Langmuir izotermi, Freundlich izotermi, Temkin ve Dubinin-Radushkevich izoterm modelleri yardımıyla incelenmiştir.

\subsubsection{Langmuir İotermi}

Langmuir modeli, enerjisel olarak eşdeğer bölgelerde bir tek tabakalı sorpsiyonun gerçekleştiğini varsayar. Langmuir denklemi aşağıdaki eşitlik olarak verilmiştir (Kong ve ark., 2016):

$$
\begin{aligned}
& \frac{C_{e}}{q_{e}}=\frac{1}{q_{\max } b}+\frac{1}{q_{\max }} C_{\mathrm{e}} \\
& R_{L}=\frac{1}{1+b C_{0}}
\end{aligned}
$$

$\mathrm{q}_{\mathrm{e}}\left(\mathrm{mg} \mathrm{g}^{-1}\right)$ adsorban üzerine adsorbe edilen metal iyonlarının miktarıdı, $\mathrm{C}_{\mathrm{e}}\left(\mathrm{mg} \mathrm{L}^{-1}\right)$ çözeltide toryum denge konsantrasyonu, $\mathrm{b}$ ( $\mathrm{L} \mathrm{mg}$ $\left.{ }^{1}\right)$ ve qmax $\left(\mathrm{mg} \mathrm{g}^{-1}\right)$ Langmuir sirasıyla adsorpsiyon enerjisi ve adsorpsiyon kapasitesiyle ilgili sabitler. Boyutsuz ayırma faktörü olan $R_{L}$, sorbat ve sorbent arasındaki afiniteyi tahmin etmek için kullanılabilir. $R_{L}$ değeri, emilim işlemini şu şekilde açıklar: $R_{L}>1$, olumsuz; $\mathrm{R}_{\mathrm{L}}=1$, doğrusal; $0<\mathrm{R}_{\mathrm{L}}<1$, uygun ve $\mathrm{R}_{\mathrm{L}}=0$, geri döndürülemez ( Bulut ve ark., 2018).

\subsubsection{Freundlich İzotermi}

Freundlich izotermi bilinen en eski ilişkidir ve sorpsiyon işleminin ideal olmayan, geri dönüşümlü ve çok katmanlı olduğunu varsayar. Model denklemi aşağıdaki şekilde yazılmıştır (Chen ve ark, 2017).

$$
\ln q_{e}=\ln K_{f}+\frac{1}{n} \ln C_{e}
$$

Eşitlikte; $\mathrm{q}_{\mathrm{e}}\left(\mathrm{mg} \mathrm{g}^{-1}\right)$, radyonüklidin dengede emme kapasitesidir, $\mathrm{K}_{\mathrm{f}}\left(\mathrm{mg}^{1-(1 / \mathrm{n})} \mathrm{L}^{1 / \mathrm{n}} \mathrm{g}^{-1}\right)$ Freundlich sabiti ve $\mathrm{n}$, heterojenite faktörüdür.

\subsubsection{Temkin İzotermi}


Temkin izotermi, tabakadaki tüm sorbatların sorpsiyon 1sısının, sorbent-sorbat etkileşimlerinden dolayı kapsama ile doğrusal olarak azaldığını ve ayrıca sorpsiyon işleminin, bir miktar bağlanma enerjisinin bir miktar maksimum bağlanma enerjisine kadar düzgün bir şekilde dağılmasıyla karakterize olduğunu varsayar. Bu model aşağıdaki denklemle ifade edilir (Rahmani-Sani ve ark., 2015).

$$
q_{e}=\mathrm{B} \ln \left(K_{T}\right)+\mathrm{B} \ln \left(C_{e}\right)
$$

Buradaki; $\mathrm{K}_{\mathrm{T}}\left(\mathrm{Lg}^{-1}\right)$, maksimum bağlama enerjisine karşılık gelen denge bağlanma sabitidir ve B sabiti, emilim 1sısı ile ilgilidir ( $\mathrm{B}=\mathrm{RT} / \mathrm{b})$.

\subsubsection{Dubinin-Radushkevich İzotermi}

Dubinin-Radushkevich (D-R) izoterm modeli, sorpsiyon eğrilerinin özelliklerinin sorbentin gözenekli yapısı ile ilişkili olduğunu varsaymaktadır. Model denklemi aşağıdaki denklemler olarak verilmiştir (Khalili ve Al-Banna, 2015):

$$
\begin{aligned}
& \ln q_{e}=\ln q_{0}-\beta \varepsilon^{2} \\
& \varepsilon=\mathrm{RT} \ln \left(1+\left(1 / \mathrm{C}_{\mathrm{e}}\right)\right.
\end{aligned}
$$

Burada; $\varepsilon$ Polanyi potansiyeli, R (8.314 J/mol.K) gaz sabiti, T (K) sıcaklık, $\mathrm{C}_{\mathrm{e}}$ (mol/L) denge derişimi, q $\mathrm{q}_{0}$ (mol/g) maksimum emilimdir DR modeline göre kapasite ve $\beta\left(\mathrm{mol} / \mathrm{J}^{2}\right)$, sorpsiyon enerjisine bağlı sabittir. Ortalama soğurma enerjisi (E, J/mol) aşağıdaki gibi hesaplanır:

$$
E=\frac{1}{\sqrt{2 \beta}}
$$

E büyüklüğü, fiziksel ya da kimyasal olup olmadığına göre, sorpsiyon işlemi tipi hakkında fikir verebilir.

\subsection{Termodinamik Çalıșmalar}

Adsorpsiyon işlemi için termodinamik parametreler [entalpi değişimi $\left(\Delta \mathrm{H}^{\circ}\right)$, entropi değişimi $\left(\Delta \mathrm{S}^{\circ}\right)$ ve Gibbs serbest enerji değişimi $\left(\Delta \mathrm{G}^{\circ}\right)$ ] aşağıdaki şekilde hesaplanmaktadır (Liu ve ark., 2017):

$$
\ln K_{d}=\frac{\Delta S^{\mathrm{o}}}{R}-\frac{\Delta H^{\mathrm{o}}}{R T}
$$

$\Delta \mathrm{G}^{\circ}=\Delta \mathrm{H}^{\circ}-\mathrm{T} \Delta \mathrm{S}^{\circ}$

$$
K_{d}=\frac{C_{A}}{C_{S}}
$$

Eşitlikte; $\mathrm{K}_{\mathrm{d}}$, termodinamik dağılım katsayısıdır, T, sıcaklık $(\mathrm{K})$ ve $\mathrm{R}$, gaz sabitidir $\left(8.3145 \mathrm{~J} \mathrm{~mol}^{-1} \mathrm{~K}^{-1}\right)$. $\mathrm{C}_{\mathrm{A}}$ ve $\mathrm{C}_{\mathrm{S}}$; dengede $(\mathrm{mol} / \mathrm{L})$ adsorbe edilmiş uranyum miktarı (sırasılla mol/L) ve dengede kalan (solüsyonda kalan miktar) (mol/L). $\Delta \mathrm{S}^{\circ}$ ve $\Delta \mathrm{H}^{\circ}$ değerleri ln $\mathrm{Kd}$ ve $1 / \mathrm{T}$ arasında çizilen grafiğin eğiminden hesaplanmıştır. $\Delta \mathrm{G}^{\circ}$ değeri yukarıdaki denklemden bulunur.

\section{Araştırma Sonuçları ve Tartışma}

\subsection{Karakterizasyon Çalışmaları}

\subsubsection{FTIR Analizi}

Adsorban olarak kullanılmak üzere üç aşamada sentezlenen monomer, polimer ve amidoksimatlı polimer aşamalarının yapısal karakterizasyonu Bio-Rad-Win-IR model FT-IR spektrofotometresi kullanılarak yapılmıştır. Spektrumlar, $4000-400 \mathrm{~cm}^{-1}$ aralığında tarama yapılarak elde edilmiştir.

FT-IR spektrumunda elde edilen spektrumlar Şekil 4'te verilmektedir. Her bir grup belli bir absorpsiyon enerji bandına sahip olduğu için FT-IR spektroskopisi ile N-(3,4-disiyanofenil) akrilamid monomeri, poli[N-(3,4-disiyanofenil) akrilamid]polimeri ve amidoksimatlı poli[N- (3,4-disiyanofenil) akrilamid] üzerindeki fonksiyonel gruplar tanımlanabilir.

Şekil 4'te N-(3,4-disiyanofenil) akrilamid'e ait FT-IR spektrumu incelendiğinde $3317 \mathrm{~cm}^{-1}$ enerji bandında O-H ve N-H gerilim titreşimi; $3097 \mathrm{~cm}^{-1}$ 'de aromatik C-H gerilimi; $2978 \mathrm{~cm}^{-1}$, de alifatik gruplardaki $\left(-\mathrm{CH}_{2},-\mathrm{CH}_{3}\right.$ ve $\left.-\mathrm{CH}_{2} \mathrm{CH}_{3}\right)$ asimetrik ve simetrik C-H gerilme titreşimleri; $2233 \mathrm{~cm}^{-1}$ de $-\mathrm{C} \equiv \mathrm{N}$ gerilim titreşimi; $1701 \mathrm{~cm}^{-1}$ 'de $\mathrm{C}=\mathrm{O}$ gerilim titreşimi; $1535-1492 \mathrm{~cm}^{-1}$ enerji bandında aromatik halka $\mathrm{C}=\mathrm{C}$ gerilim titreşimi; $1195 \mathrm{~cm}^{-1}$ 'de $\mathrm{CN}$ gerilim titreşimi; $895-665 \mathrm{~cm}^{-1}$ bandında ise alken $=\mathrm{C}-\mathrm{H}$ bükülmesi gözlenmiştir (Gao ve ark., Liu ve ark., 2017).

poli[N- (3,4-disiyanofenil) akrilamid]'ın FT-IR spektrumu incelendiğinde (Şekil 4), $3417 \mathrm{~cm}^{-1}$ bandında O-H ve N-H gerilme titreşimleri; $3097 \mathrm{~cm}^{-1}$ 'de aromatik C-H gerilimi; $2927 \mathrm{~cm}^{-1}$ de alifatik gruplardaki $\left(-\mathrm{CH}_{2},-\mathrm{CH}_{3}\right.$ ve $\left.-\mathrm{CH}_{2} \mathrm{CH}_{3}\right)$ asimetrik ve simetrik C- 
$\mathrm{H}$ gerilme titreşimleri; $2233 \mathrm{~cm}^{-1}$ de $-\mathrm{C} \equiv \mathrm{N}$ gerilim titreşimi; $1697 \mathrm{~cm}^{-1}$, de $\mathrm{C}=\mathrm{O}$ gerilim titreşimi; $1527-1454 \mathrm{~cm}^{-1}$ enerji bandında aromatik halka $\mathrm{C}=\mathrm{C}$ gerilim titreşimi; $1099 \mathrm{~cm}^{-1}$ ' $\mathrm{de}$ monomerden farklı olarak $\mathrm{NH}_{2}$ gerilim titreşimi ile $906 \mathrm{~cm}^{-1}$ ' $\mathrm{de}=\mathrm{N}-\mathrm{OH}$ gerilim titreşimi; 844-794 $\mathrm{cm}^{-1}$ bandında ise alken $=\mathrm{C}-\mathrm{H}$ bükülmesi belirlenmiştir.

Amidoksimatlı poli[N- (3,4-disiyanofenil) akrilamid]' In FT-IR spektrumunda ise 3253-3142 $\mathrm{cm}^{-1}$ bandında O-H ve N-H bağlarının gerilim titreşimleri; $2918 \mathrm{~cm}^{-1}$ 'de alifatik gruplardaki $\left(-\mathrm{CH}_{2},-\mathrm{CH}_{3}\right.$ ve $\left.-\mathrm{CH}_{2} \mathrm{CH}_{3}\right)$ asimetrik ve simetrik $\mathrm{C}-\mathrm{H}$ gerilme titreşimleri gözlenmiş; fakat monomer ve polimerde $2233 \mathrm{~cm}^{-1}$ 'de bulunan $-\mathrm{C} \equiv \mathrm{N}$ grubuna ait pik amidoksimasyon sonucu kaybolmuştur. 1658 $\mathrm{cm}^{-1}$ de $\mathrm{C}=\mathrm{N}$ gerilim titreşimi; $1598 \mathrm{~cm}^{-1}$ de aromatik halka $\mathrm{C}=\mathrm{C}$ gerilim titreşimi; $1365 \mathrm{~cm}^{-1}$ de N-O gerilim titreşimi; $1232-1055$ $\mathrm{cm}^{-1}$ bandında C-N gerilim titreşimi; $947 \mathrm{~cm}^{-1}$ de $=\mathrm{N}-\mathrm{OH}$ gerilim titreşimi; $831-686 \mathrm{~cm}^{-1}$ bandında ise alken $=\mathrm{C}-\mathrm{H}$ bükülmesi tespit edilmiştir. Bu sonuçlara göre $\mathrm{N}$-(3,4-disiyanofenil) akrilamid ve poli[N-(3,4-disiyanofenil) akrilamid] $2233 \mathrm{~cm}^{-1}$ bandında bulunan $\mathrm{C} \equiv \mathrm{N}$ grubuna ait piklerin kaybolması ile 1658 ve $947 \mathrm{~cm}^{-1}$, de gözlenen $\mathrm{C}=\mathrm{N}$ ve $=\mathrm{N}-\mathrm{OH}$ bantlarının oluşumu amidoksimasyonun varlığını kanıtlamıştır (Baybaş ve ark., 2010). Amidoksimatlı poli[N-(3,4-disiyanofenil) akrilamid]'in fonksiyonel grupları incelendiğinde, uranyum adsorpsiyonu için uygun bir adsorban olduğu görülmektedir.

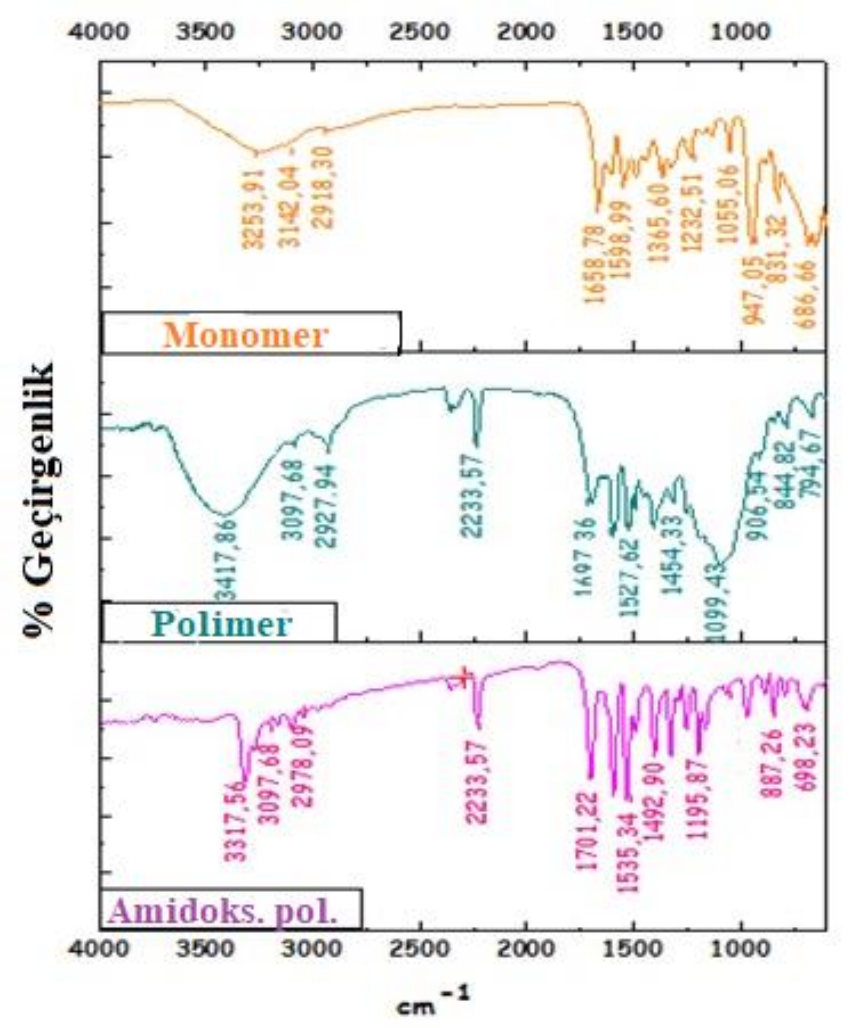

Şekil 4. N-(3,4-disiyanofenil) akrilamid, poli[N-(3,4-disiyanofenil) akrilamid] ve amidoksimatlı poli[N-(3,4-disiyanofenil) akrilamid]'in FT-IR grafikleri

Amidoksimatlı poli[N-(3,4-disiyanofenil) akrilamid] adsorbanının adsorpsiyon öncesi ile uranyum iyonları adsorpsiyonu sonrası elde edilen FTIR grafiği Şekil 5 'te verilmiştir. 


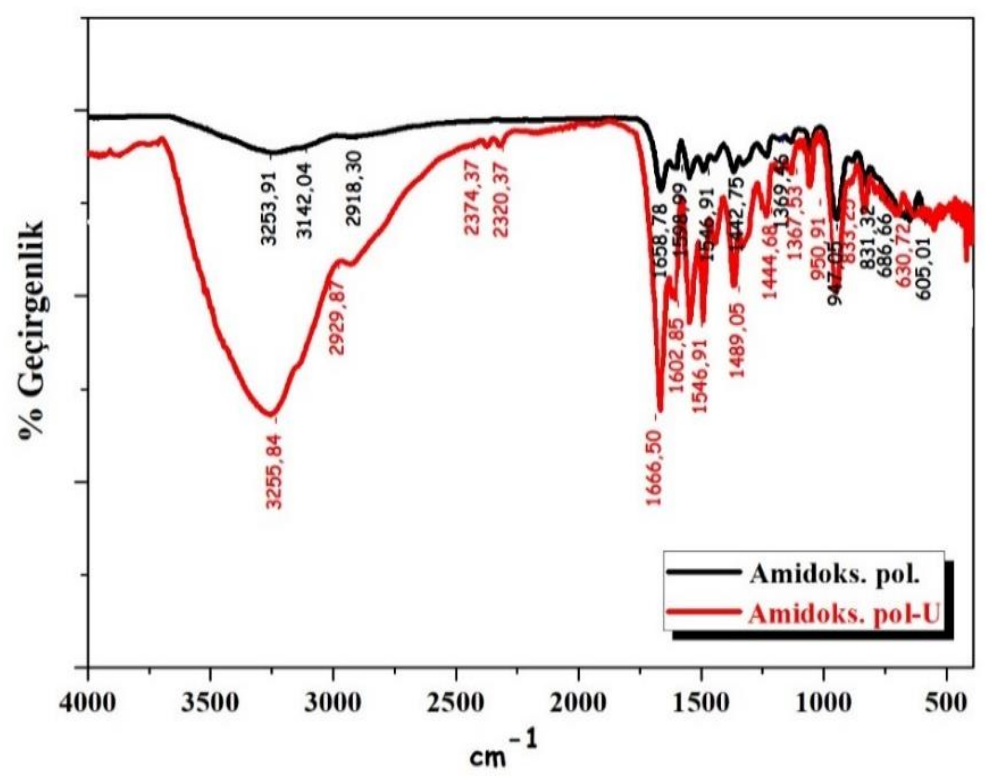

Şekil 5. Uranyum adsorpsiyonu öncesi ve sonrasına ait FT-IR grafikleri

\subsubsection{TGA/DSC Analizi}

poli[N-(3,4-disiyanofenil) akrilamid] ile amidoksimatlı poli[N-(3,4-disiyanofenil) akrilamid]'in termal kararlılıkları, camsı geçiş sıcaklığı ve erime sıcaklık değerleri, TGA/DSC analizleri Setaram Labsys Evo Gravimetric Analyzer 1600 model cihazı kullanılarak belirlendi. Yaklaşık 4-6 mg numune seramik bir kroze içine yerleştirilerek 50-1000 ${ }^{\circ} \mathrm{C}$ aralığında Argon atmosferi altında $100 \mathrm{~mL} / \mathrm{dak}$ akışla $10^{\circ} \mathrm{C} /$ dak 1 sıtma hızında analiz edildi. poli[N-(3,4-disiyanofenil) akrilamid] ile amidoksimatlı poli[N-(3,4-disiyanofenil) akrilamid]'e ait TGA termogramları Şekil 6 ve 7'de verilmiştir.

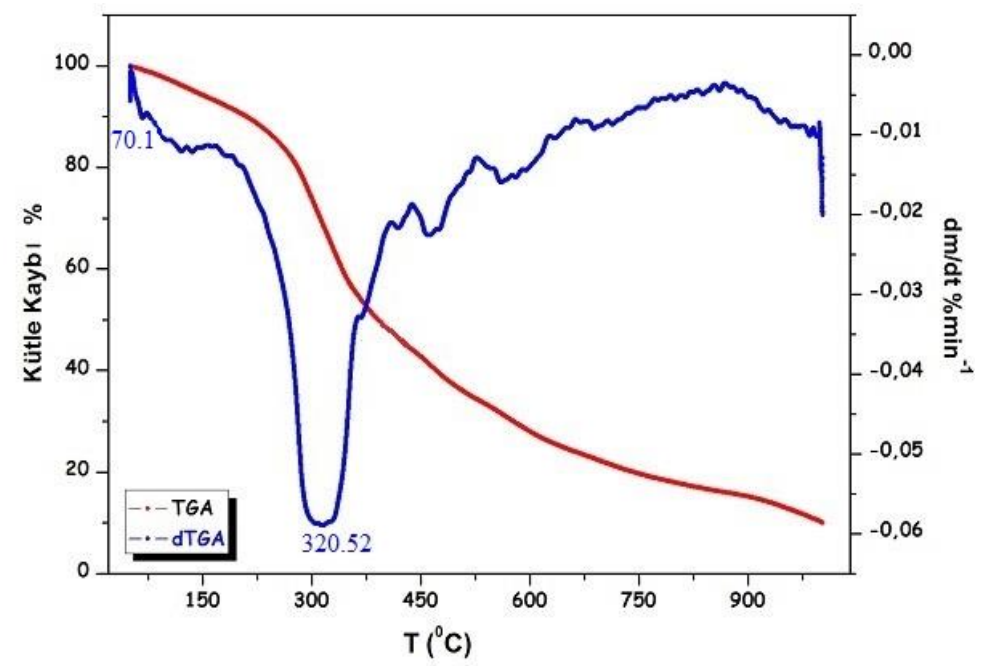

Şekil 6. poli[N-(3,4-disiyanofenil) akrilamid]'in TGA termogramı

poli[N-(3,4-disiyanofenil) akrilamid]'e ait TGA termogram incelendiğinde (Şekil 6), iki basamaklı bir bozunma olduğu görülmektedir. $\mathrm{Bu}$ bozunmalar türev grafiğinden de görüldüğ̈̈ üzere $70^{\circ} \mathrm{C}$ ve $320^{\circ} \mathrm{C}$ 'de başlamaktadır. 1 . bozunma basamağında polimer içindeki absorplanmış su, çözücü ve monomer gibi küçük mol kütleli bileşenlerden oluşan yaklaşık \%8'lik madde uzaklaşmaktadır. 2. bozunma basamağında polimer zincir yapısı bozunmaktadır. \%50'lik madde kaybı $390^{\circ} \mathrm{C}$ 'de gerçekleşmiştir. $1000^{\circ} \mathrm{C}^{\prime}$ ye kadar 1 sıtıldığında ise polimerin \%90’1 bozunarak geriye \%8'lik kısmı bozunmadan kalmıştır. Bu değerler, polimer zincir yapısının düzenli olduğunu ve termal geçişleri etkileyen $\mathrm{C}=\mathrm{O}$ ve $\mathrm{N}-\mathrm{H}$ grupları arasındaki moleküller arası hidrojen bağ etkileşimlerinin, termal kararlılığı arttırdığını göstermektedir (Can ve ark., 2006). 


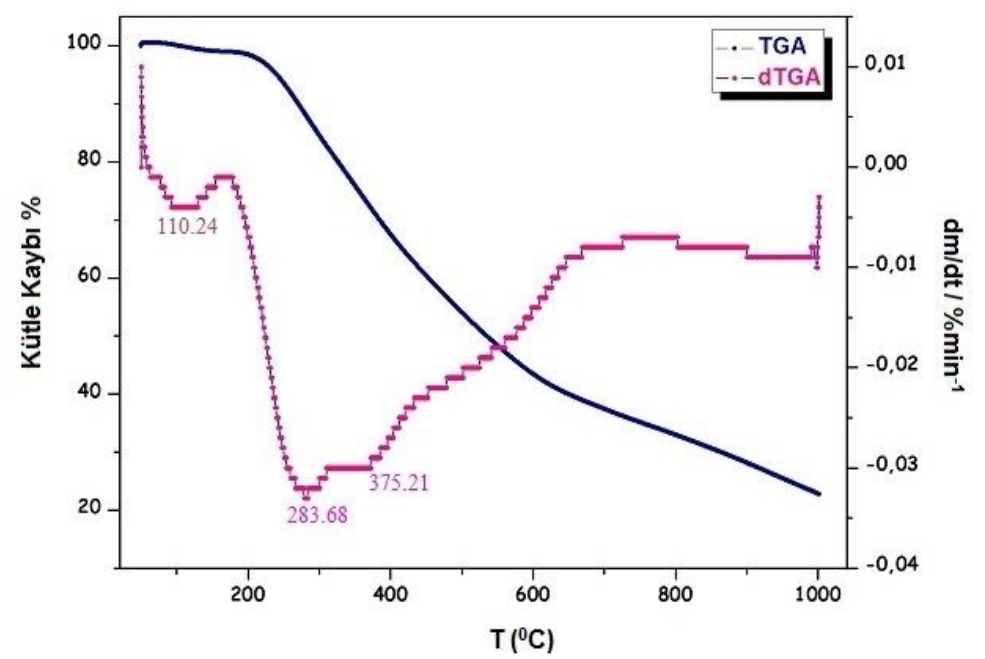

Şekil 7. Amidoksimatlı poli[N-(3,4-disiyanofenil) akrilamid]'in TGA termogramı

Amidoksimatlı poli[N-(3,4-disiyanofenil) akrilamid]'e ait TGA termogramı (Şekil 7) polimerin 1sıl kararlılı̆̆ının amidoksim dönüşümü ile arttığ 1 görülmektedir. Ayrıca, amidoksimasyon işlemi bozunmanın yavaşlamasına da neden olmaktadır. İki basamaklı bir bozunma gerçekleşmiştir. İlk basamakta $110^{\circ} \mathrm{C}$ 'de başlayan bozunma ile yapıya tutunan suyun uzaklaşması sonucu \%2'lik bir madde kaybı oluşmaktadır. İkinci basamakta ise $283^{\circ} \mathrm{C}$ 'de yer alan pik $\mathrm{C} \equiv \mathrm{N}$ gruplarının amidoksim gruplarına dönüşmesiyle oluşan bozunma pikini, $375^{\circ} \mathrm{C}$ 'deki pik ise polimere ait bozunma pikini vermektedir. Görüldügü gibi yapıya dahil olan hacimli amidoksim grupları polimer zincirindeki gruplar arasında oluşan muhtemel H-bağları sebebiyle polimerin bozunmasın $1320^{\circ} \mathrm{C}^{\prime}$ den $375^{\circ} \mathrm{C}^{\prime}$ ye kaydırmıştır. \%50'lik bozunmanın gerçekleştiği sıcaklık $532^{\circ} \mathrm{C}$ 'ye yükselmiştir. $1000^{\circ} \mathrm{C}$ 'de bozunan amidoksimlenmiş polimerin oranı \%78'dir. \%22‘lik kısmı ısıtma işlemi tamamlandığında bozunmadan kalmıştır. Bu değerler göz önüne alındığında, amidoksimasyon sonucu yapının 1 sıl kararlılığının daha da arttığı söylenebilir.
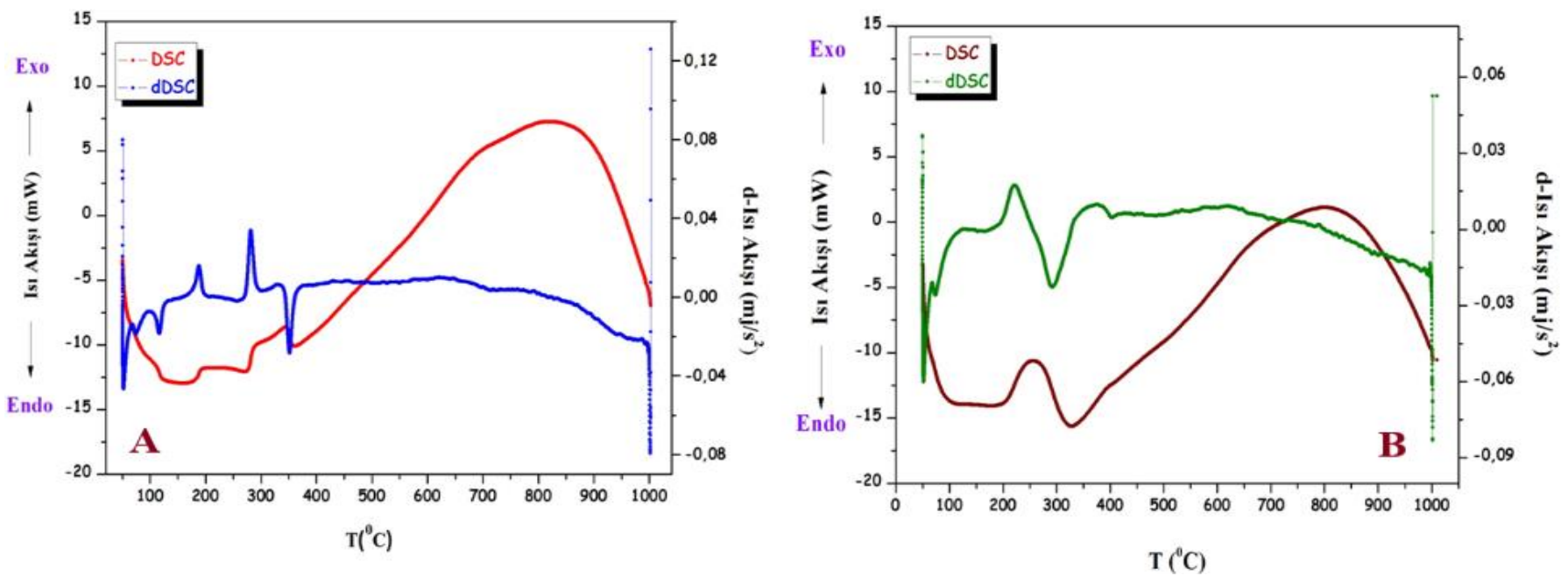

Şekil 8. A) poli[N-(3,4-disiyanofenil) akrilamid]'in ve B) amidoksimatlı poli[N-(3,4-disiyanofenil) akrilamid]'in DSC termogramı

DSC termogramları incelenerek polimer yapıların camsı durumdan kauçuğumsu duruma geçişini karakterize eden camsı geçiş sıcaklığ 1 ve 1 sı etkisi ile polimerlerde oluşan fiziksel ve kimyasal değişimler açıklanabilmektedir. Şekil 8/a'da poli[N-(3,4disiyanofenil) akrilamid] ait DSC eğrisi incelendiğinde, camsı geçiş sıcaklığının $\left(\mathrm{T}_{\mathrm{g}}\right) 70^{\circ} \mathrm{C}$, erime sicaklığının $\left(\mathrm{T}_{\mathrm{g}}\right) 271^{\circ} \mathrm{C}$ olarak tespit edildiği ve yapıda egzotermik kristal oluşumunun gerçekleştiği görülmektedir. Şekil 8/b'de amidoksimatlı poli[N-(3,4-disiyanofenil) akrilamid]'e ait DSC eğrisinden de $\mathrm{T}_{\mathrm{g}}$ 'nin $110^{\circ} \mathrm{C}$ ve $\mathrm{T}_{\mathrm{e}}$ 'nin $327^{\circ} \mathrm{C}$ olduğu ve yine yapıda egzotermik kristal oluşumu meydana geldiği tespit edilmiştir. Polimerin amidoksimasyonu sonucu yapıdaki çapraz bağ oranı arttığı için $T_{g}$ ve $T_{e}$ değerleri de artmıştır. Amidoksimatlı polimer daha yüksek ısıl kararlılığa ulaşmıştır.

\subsection{Uranyumun Amidoksimatlı poli[N-(3,4-disiyanofenil) akrilamid] Üzerine Adsorpsiyonu}

Amidoksimatlı poli[N-(3,4-disiyanofenil) akrilamid] adsorbanı kullanılarak, sulu çözeltilerden U(VI) iyonlarının adsorpsiyonu kesikli (batch) yöntemle çalışılmıştır. Adsorpsiyon üzerine etki eden dört farklı parametre incelenmiştir. Bu parametreler; temas süresi, $\mathrm{pH}$, başlangıç konsantrasyonu ve sıcaklık etkisidir. 


\subsection{1. pH etkisi}

pH Çözelti pH'ı, adsorpsiyon işlemini etkileyen en önemli parametrelerden biridir. pH miktarı, adsorbanın yüzey yükünü, iyonlaşma derecesini ve adsorbent karakteristiklerini belirler. pH'nın uranyum alımı üzerindeki etkisini değerlendirmek için $0.001 \mathrm{~g}$ adsorban, $20 \mathrm{mg} / \mathrm{L}$ 'lik $10 \mathrm{ml}$ uranyum çözeltisi ile farklı pH değerlerinde (3.5 ila 6.0) 7 dakika boyunca $25^{\circ} \mathrm{C}$ sıcaklığında karıştırıldı. Çözeltinin pH'ı, uygun miktarlarda asetik asit ve sodyum hidroksit ilave edilerek ayarlandı. Daha sonra karışım filtre kâğı̆ı ile süzüldü. Süzüntüdeki U(VI) iyonlarının kalıntı konsantrasyonları UV spektrofotometre ile belirlenmiştir (Şekil 9). Çalışmamızda optimum $\mathrm{pH} 4.0$ olarak bulunmuştur.

pH 1-4 arasında $\mathrm{H}_{3} \mathrm{O}^{+}$ve $\mathrm{UO}_{2}{ }^{+2}$ iyonlarının adsorpsiyonunda bir yarışma söz konusudur. Sulu çözeltilerde $\mathrm{pH}<2,5$ 'ta uranil iyonları oldukça stabildir. pH 4 'te baskın tür olarak $\mathrm{UO}_{2}{ }^{+2}$ ön plana çıkmaktadır (Sorg, 1991; Qadeer ve Saldem, 1997).

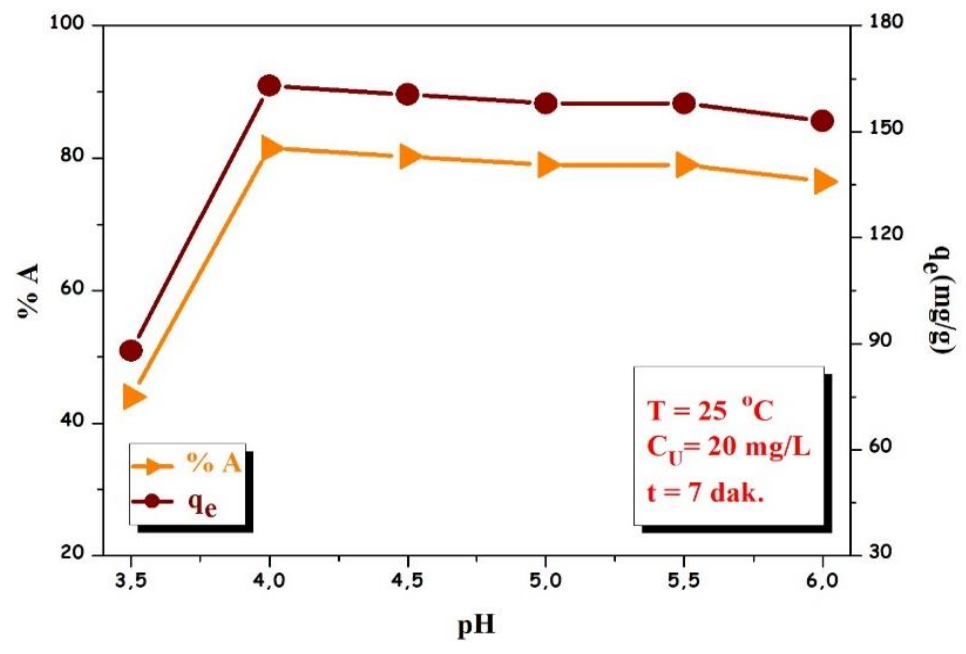

Şekil 9. pH’nın U(VI) adsorpsiyonu üzerine etkisi

\subsubsection{Temas süresi etkisi ve kinetik çalışmalar}

Temas süresi etkisi için; $20 \mathrm{mg} / \mathrm{L}$ 'lik U(VI) çözeltilerinin $25^{\circ} \mathrm{C}$ sıcaklık ve pH $3.5^{\prime} \mathrm{ta}, 0.001 \mathrm{~g}$ adsorban tarafindan değişen sürelerde (1-10 dakika) adsorpsiyonu incelenerek, elde edilen veriler Şekil 10' da gösterilmiştir. Optimum temas süresi 7 dakika olarak belirlenmiş̧tir.

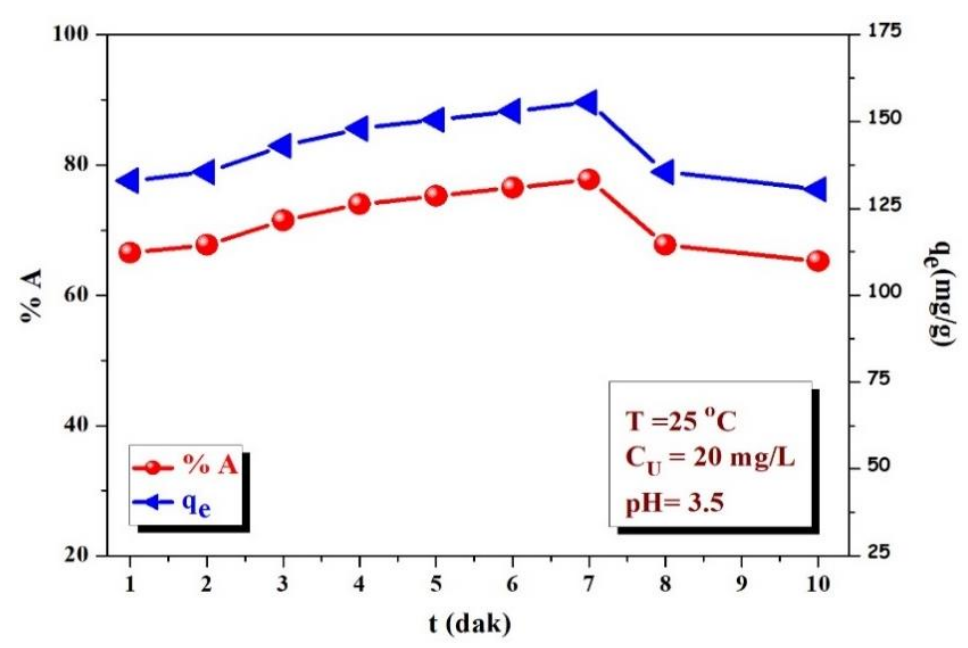

Şekil 10. Temas süresinin U(VI) adsorpsiyonu üzerine etkisi

Temas süresi verilerinin kinetik modellere ait matematiksek denklemlere $(4,5)$ uygulanmasyyla elde edilen grafikler Şekil 11' de kinetik modellerin hesplanan parametreleri ise Tablo 1'de gösterilmektedir. 

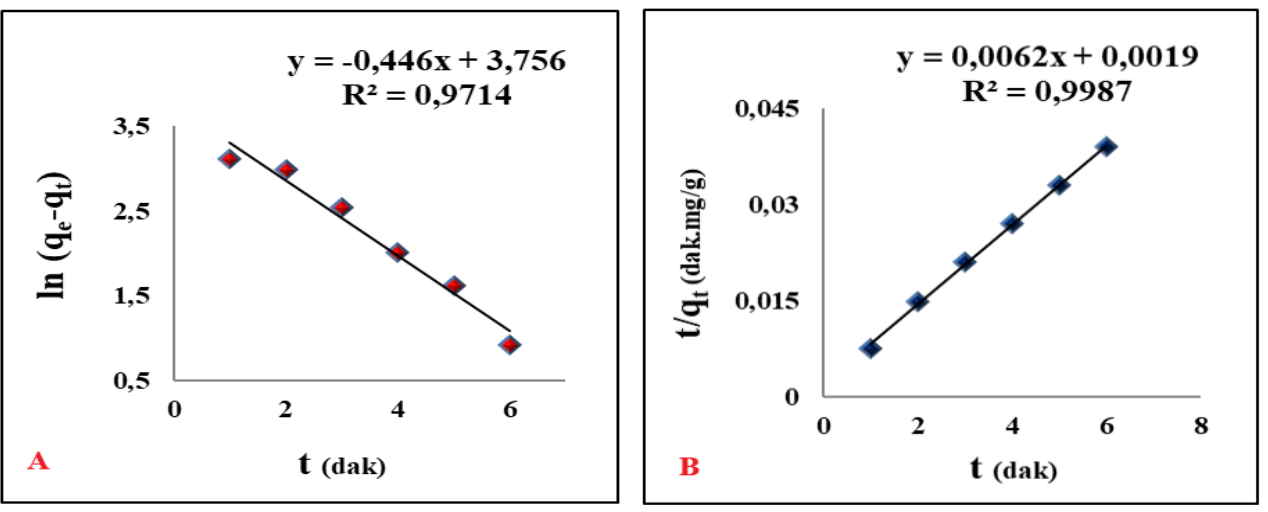

Şekil 11. Uranyum adsorpsiyonu için (a) pseudo birinci derece (b) pseudo ikinci derece adsorpsiyon kinetiği

Tablo 1. Uranyum Adsorpsiyonu için Kinetik Parametreler

\begin{tabular}{|c|c|c|c|c|c|c|c|}
\hline \multicolumn{4}{|c|}{ Pseudo birinci derece } & \multicolumn{3}{|c|}{ Pseudo ikinci derece } & \multirow{2}{*}{$\begin{array}{c}\text { Deneysel } \\
q_{\text {exp }} \\
(m g / g)\end{array}$} \\
\hline & $\begin{array}{c}k_{1} \\
\left(d a k^{-1}\right)\end{array}$ & $\begin{array}{c}q_{e l} \\
(m g / g)\end{array}$ & $R_{l}^{2}$ & $\begin{array}{c}k_{2} \\
\left(g m g^{-1} d a k^{-1}\right)\end{array}$ & $\begin{array}{c}q_{e 2} \\
(\mathrm{mg} / \mathrm{g})\end{array}$ & $R_{2}^{2}$ & \\
\hline$U(V I)$ & 0.45 & 42.78 & 0.9714 & 0.084 & 161.3 & 0.9987 & 155.5 \\
\hline
\end{tabular}

Tablo 1'de gösterilen pseudo birinci ve pseudo ikinci dereceli modellerin parametre sonuçları, pseudo ikinci kinetik modelinin korelasyon katsayısının $\left(\mathrm{R}^{2}\right) 0.9879$ olduğunu ve teorik kapasitenin $\left(\mathrm{q}_{\mathrm{e}}\right)$ deneysel kapasiteye daha yakın olduğunu $(161.3 \mathrm{mg} / \mathrm{g})$ göstermektedir. Bu sonuçlar, pseudo ikinci derece kinetik modelinin hız kontrol basamağı olarak adsorpsiyon mekanizmasıyla uyumlu olduğunu göstermektedir.

\subsubsection{Başlangıç konsantrasyonu etkisi ve adsorpsiyon izotermleri}

Uranyumun adsorpsiyon davranışını etkileyebilen adsorpsiyon sistemindeki en önemli parametrelerden biri, metal iyonunun ilk konsantrasyonudur. U(VI) iyonlarının başlangıç konsantrasyonunun, amidoksimatlı poli[N-(3,4-disiyanofenil) akrilamid]'in adsorpsiyon kapasitesi üzerindeki etkisi, bir dizi başlangıç iyon konsantrasyonu kullanılarak incelenmiştir. Sonuçlar Şekil 12 'de gösterilmektedir. U(VI) iyonları için optimum başlangıç konsantrasyon değeri $8 \mathrm{mg} / \mathrm{L}$ olarak belirlenmiştir.

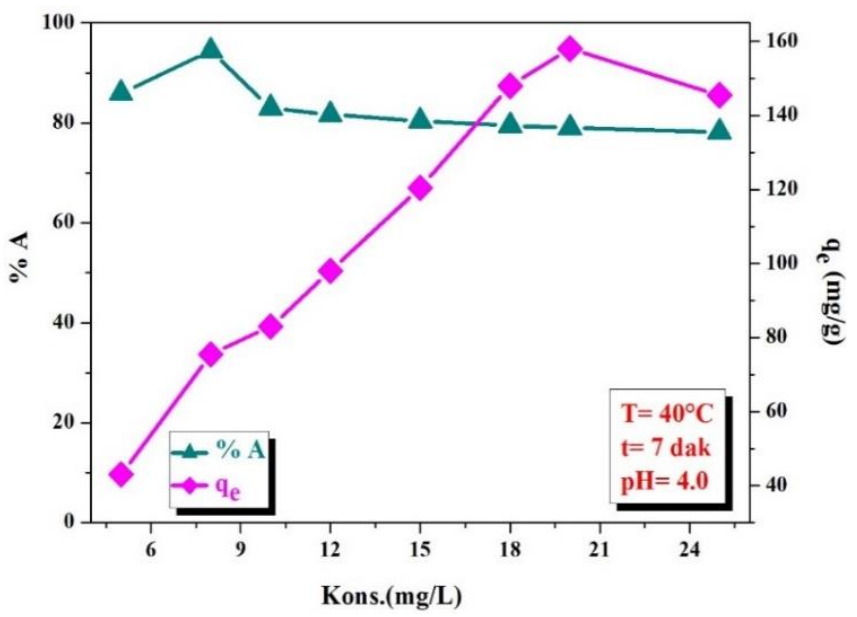

Şekil 12. Başlangıç konsantrasyonunun U(VI) adsorpsiyonu üzerine etkisi

Denge verileri, deney sonuçlarını ve gerçek adsorpsiyon davranışını açıklamak için sık kullanılan izoterm modelleri, yani Langmuir, Freundlich, Temkin ve Dubinin-Radushkevich (D-R izotermleri kullanılarak modellenmiştir. Adsorpsiyon izoterminin araştırılmasında $5-25 \mathrm{mg} / \mathrm{L}$ aralığındaki uranyum çözeltileri kullanılmıştır. Langmuir, Freundlich, Temkin ve Dubinin-Radushkevich izoterm modellerine ait grafikler Şekil 13’te, izoterm sabitlerinin hesaplanan sonuçları ise Tablo 2'de gösterilmiştir. 

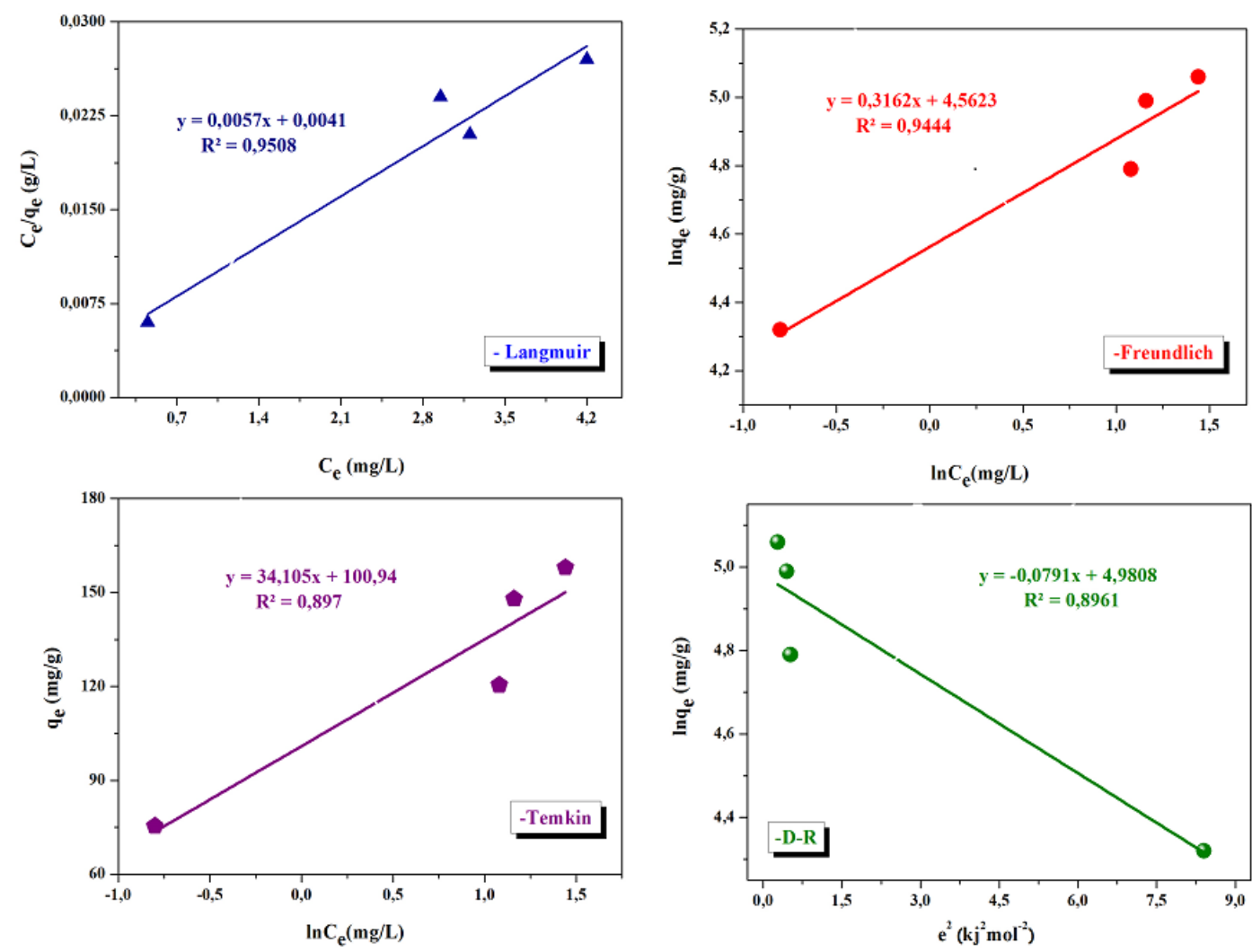

Şekil 13. Amidoksimatlı poli[N-(3,4-disiyanofenil) akrilamid] üzerine uranyum adsorpsiyonu için izoterm grafikleri

Tablo 2. Uranyum Adsorpsiyonu için İzoterm Parametreleri

\begin{tabular}{c|c|c|c|c|c|c|c}
\hline \multicolumn{5}{c|}{ Langmuir } & \multicolumn{3}{c}{ Freundlich } \\
\hline & $q_{\max }(\mathrm{mg} / \mathrm{g})$ & $R_{L}$ & $b(L / m g)$ & $R^{2}$ & $K_{f}(\mathrm{mg} / \mathrm{g})$ & $n$ & $R^{2}$ \\
\hline$U(V I)$ & 175.4 & 0.09 & 1.34 & 0.9508 & 95.8 & 3.16 & 0.9444 \\
\hline \multicolumn{3}{|c|}{ Dubinin-Radushkevich } & \multicolumn{3}{c}{ Temkin } \\
\hline & $q_{m}(\mathrm{mg} / \mathrm{g})$ & $\beta\left(\mathrm{mol}^{2} \mathrm{~kJ}^{-2}\right)$ & $E(\mathrm{~kJ} / \mathrm{mol})$ & $R^{2}$ & $K_{T}(\mathrm{~L} / \mathrm{g})$ & $B(\mathrm{~J} / \mathrm{mol})$ & $R^{2}$ \\
\hline$U(V I)$ & 145.6 & 0.08 & 1.77 & 0.8961 & 19.3 & 34.1 & 0.897 \\
\hline
\end{tabular}

Langmuir, Freundlich, Dubinin-Radushkevich ve Temkin izoterm parametreleri ve korelasyon katsayıları Tablo 2'de verilmiştir. Korelasyon katsayıları $\left(\mathrm{R}^{2}\right)$ karşılaştırıldığında, Langmuir modelinin diğer izoterm modellerine göre daha yüksek korelasyon katsayısına sahip olduğu görülmektedir. Ayrıca 0.09 olarak belirlenen $\mathrm{R}_{\mathrm{L}}$ değeri $\left(0<\mathrm{R}_{\mathrm{l}}<1\right)$, amidoksimatlı poli[N-(3,4-disiyanofenil) akrilamid] adsorbanının uranyumun adsorpsiyonu için uygun olduğunu göstermektedir. Bu nedenle, adsorpsiyon süreci Langmuir izoterm modeli tarafından daha uygun şekilde açıklanmaktadır. Langmuir izoterminin deneysel verilere çok iyi uyması, aktif bölgelerin amidoksimatlı poli[N-(3,4-disiyanofenil) akrilamid] üzerindeki homojen dağılımına bağlı olabilir. Çünkü Langmuir denklemi yüzeyin homojen olduğunu varsayar. Tablo 2'deki Dubinin-Radushkevich izoterminin E değeri $1.77 \mathrm{kj} / \mathrm{mol}$ olduğu için de uranyum adsorpsiyonunun fiziksel adsorpsiyonla gerçekleştiği düşünülmektedir.

\subsubsection{Sicaklık etkisi ve termodinamik çalışmalar}

Sıcaklığın, amidoksimatlı poli[N-(3,4-disiyanofenil) akrilamid] adsorbanı üzerindeki uranyum adsorpsiyonu üzerindeki etkisini incelemek için, 15 ile $40{ }^{\circ} \mathrm{C}$ arasında değişen farklı sıcaklıklar kullanılarak bir dizi adsorpsiyon deneyi yapıldı. Bu deney serisinde diğer parametreler sabit tutuldu, yani $0.001 \mathrm{~g}$ adsorban, başlangıçta $20 \mathrm{mg} / \mathrm{L}$ uranyum konsantrasyonu, pH 4.0 ve $7 \mathrm{dakika}$ temas süresi. Elde edilen sonuçlar, Şekil 14'te gösterilmiştir. Grafiğe göre, uranyum adsorpsiyon verimliliğinin artan sıcaklıkla arttığı açıktır. $\mathrm{Bu}$ adsorpsiyon reaksiyonunun bir endotermik süreç olduğunu göstermektedir. 


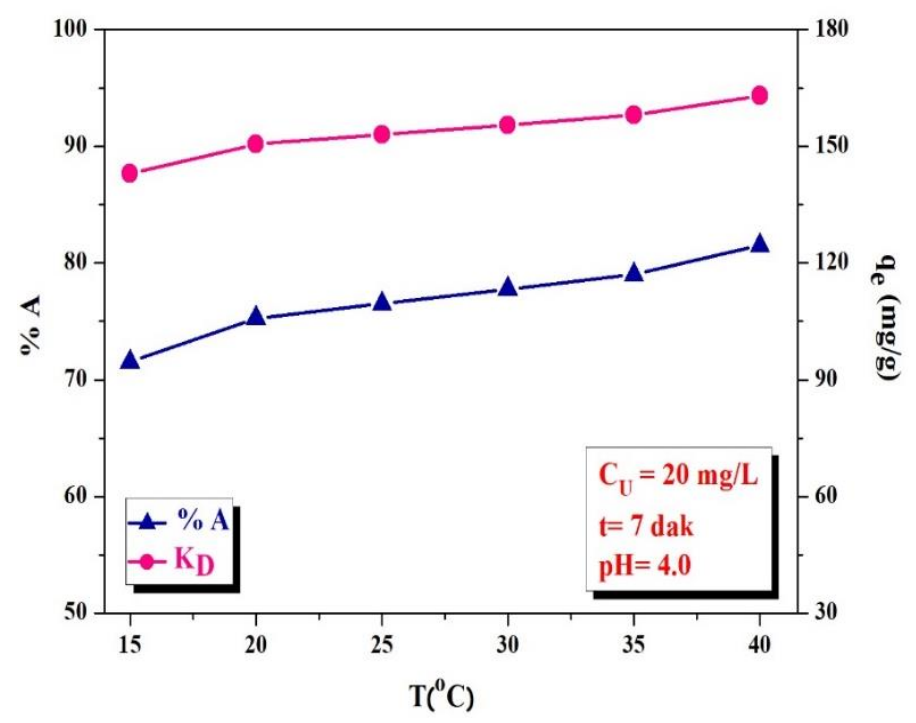

Şekil 14. Sicaklı̆̆ın U(VI) adsorpsiyonu üzerine etkisi

$\mathrm{K}_{\mathrm{d}}{ }^{\prime} \operatorname{nin} 1 / \mathrm{T}^{\prime}$ ye karşı grafiği Şekil $15^{\prime}$ te gösterilmektedir. $\Delta \mathrm{H}^{\circ}$ ve $\Delta \mathrm{S}^{\circ}$ değerleri grafiğin eğim ve kesişiminden elde edilir ve bu sonuçlar Tablo 3 'te gösterilmektedir.

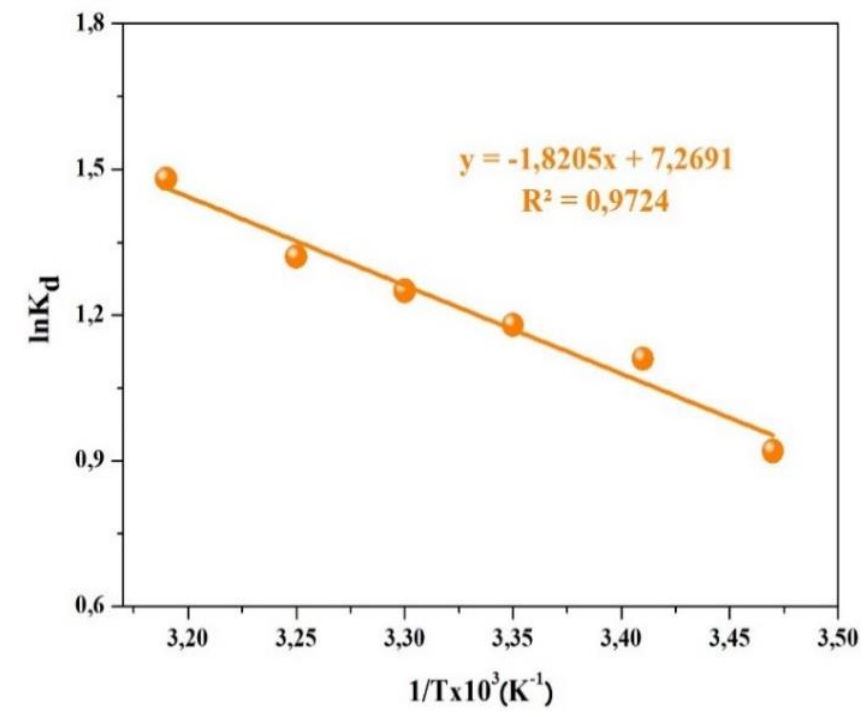

Şekil 15. U(VI) iyonlarının adsorpsiyonunda $\ln \mathrm{Kd}$ ' nin $1 / \mathrm{T}$ ile değişimi

Tablo 3. Adsorpsiyon çalışmalarının termodinamik parametreleri

\begin{tabular}{|c|c|c|c|c|c|}
\hline \multicolumn{6}{|c|}{ Termodinamik parametreler } \\
\hline & Sicaklık $(K)$ & $\Delta H^{0}(\mathrm{~J} / \mathrm{mol})$ & $\Delta S^{0}(\mathrm{~J} / \mathrm{mol} \mathrm{K})$ & $T \Delta S^{0}(\mathrm{~kJ} / \mathrm{mol})$ & $\Delta G^{0}(\mathrm{~kJ} / \mathrm{mol})$ \\
\hline \multirow{6}{*}{$U(V I)$} & 288 & \multirow{6}{*}{15.14} & \multirow{6}{*}{60} & 17.28 & -2.2 \\
\hline & 293 & & & 17.58 & -2.7 \\
\hline & 298 & & & 17.88 & -2.92 \\
\hline & 303 & & & 18.18 & -3.15 \\
\hline & 308 & & & 18.48 & -3.38 \\
\hline & 313 & & & 18.78 & -3.85 \\
\hline
\end{tabular}

Adsorpsiyonun entalpi değişimi $\left(\Delta \mathrm{H}^{\circ}\right)$ ve entropi değişimi $\left(\Delta \mathrm{S}^{\circ}\right) 15.14 \mathrm{~J} / \mathrm{mol}$ ve $60 \mathrm{~J} / \mathrm{mol} . \mathrm{K}^{\prime}$ dir. $\Delta \mathrm{H}^{\circ}$ nin pozitif değeri, $\mathrm{U}(\mathrm{VI})$ iyonlarının adsorpsiyonunun doğada endotermik olduğunu ve $\Delta S^{\circ}$ nin pozitif değerinin, adsorpsiyon sisteminin stabilitesini gösterdiğini ve adsorpsiyon prosesi sırasındaki rasgelelikteki bir artışı yansıttığını göstermektedir. Ayrıca, $\Delta \mathrm{G}^{\circ}$ değeri artan sıcaklıkla azalır, bu da uranyumun amidoksimatlı poli[N-(3,4-disiyanofenil) akrilamid] üzerine adsorpsiyon işleminin kendiliğinden olduğunu ve daha yüksek sıcaklıkların uranyum adsorpsiyonu için daha uygun olduğunu gösterir. 


\section{Sonuç}

Uranyumun sulu çözeltilerden yüksek verimli şekilde çıkarılması için yeni bir amidoksimatlı poli[N-(3,4-disiyanofenil) akrilamid] adsorbanı geliştirilmiştir. Amidoksimatlı poli[N-(3,4-disiyanofenil) akrilamid] adsorbanı, üç aşamada sentezlendi. İlk olarak N-(3,4-disiyanofenil) akrilamid monomeri sentezlenmiş ve daha sonra bu monomer AIBN başlatıcısı kullanılarak toluen ortamında polimerleştirilerek poli[N-(3,4-disiyanofenil) akrilamid] elde edilmiştir. Son aşamada ise polimer, hidroksilamin hidroklorür ile sodyum hidroksit çözeltisi içerisinde amidoksimatlanmıştır. Yapısal karakterizasyon çalışmaları için yapılan FTIR analizi sonuçlarına göre de $\mathrm{N}$-(3,4-disiyanofenil) akrilamid ve poli[N-(3,4-disiyanofenil) akrilamid]'in $2233 \mathrm{~cm}^{-1}$ bandında bulunan $\mathrm{C} \equiv \mathrm{N}$ grubuna ait piklerin kaybolması ile 1658 ve $947 \mathrm{~cm}^{-1}$, de gözlenen $\mathrm{C}=\mathrm{N}$ ve $=\mathrm{N}-\mathrm{OH}$ bantlarının oluşumu amidoksimasyonun varlığını kanıtlamaktadır. Adsorbanın ısıl davranışlarını tanımlamak amacıyla yapılan TGA/DSC analizleri sonuçlarına göre, poli[N(3,4-disiyanofenil) akrilamid]'in amidoksimasyonu sonucu yapıdaki çapraz bağ oranı arttığı için adsorbanının daha yüksek 1sıl kararlılı̆ga ulaştığı belirlenmiştir. Amidoksimatlı poli[N-(3,4-disiyanofenil) akrilamid] yapısındaki amidoksim gruplarının varlığı, bu adsorbanın uranyum adsorpsiyonu için uygun olduğunu göstermektedir.

Pseudo birinci dereceli kinetik model ve Pseudo ikinci dereceli kinetik model, amidoksimatlı poli[N-(3,4-disiyanofenil) akrilamid] üzerine uranyum adsorpsiyonu için değerlendirildi. En uygun kinetik model, pseudo ikinci dereceli kinetik model olarak bulundu. Langmuir, Freundlich, Temkin ve Dubinin-Radushkevich izotermal modelleri adsorpsiyon işlemine uygunlukları açısından incelendi. Adsorpsiyon denge verileri Langmuir izoterm modeline iyi uyum sağlamakta ve uranyumun maksimum adsorpsiyon kapasitesi $175.4 \mathrm{mg} / \mathrm{g}$ oalarak belirlenmiştir. Termodinamik parametrelerin analizi sonucunda adsorpsiyon proseslerinin kendiliğinden ve endotermik nitelikte olduğu belirlenmiş̧ir. Ayrıca, pozitif değere sahip entropi, uranyum iyonlarının amidoksimatlı poli[N-(3,4disiyanofenil) akrilamid] adsorbanına ilgi düzeyini göstermektedir.

Sonuçlar, ilk defa sentezlenen amidoksimatlı poli[N-(3,4-disiyanofenil) akrilamid] adsorbanının uranyum iyonlarının sulu çözeltilerden giderilmesinde oldukça yüksek adsorplama kapasitesine sahip olduğınu göstermiştir. Amidoksim grupları içeren bu adsorban madde, atık sulardan uranyum adsorpsiyonu için yapılacak sonraki çalışmalar için gelişmiş uranil afinitesi ve seçiciliği olan yeni polimerik malzemelerin rasyonel tasarımında temel bilgi sağlayabilir.

\section{Teșekkür}

Bu çalışma, 2015-FBE-D031 No’lu doktora projesi olarak Van Yüzüncü Yıl Üniversitesi Bilimsel Araştırma Proje Birimi Tarafından desteklenmiştir.

\section{Kaynakça}

Aycan, H.Ş., Arslan, Z.K. (2017). Adsorpsiyon-Yüzey İlişkisi Konusunun Öğretiminde Aletli Analiz Uygulamalarının Fen Bilgisi Öğretmen Adaylarının Akademik Başarılarına Etkisi. Journal of The Turkish Chemical Society, 2, 107-126.

Barber, P.S., Kelley, S.P., Rogers, R.D. (2012). Highly selective extraction of the uranyl ion with hydrophobic amidoximefunctionalized ionic liquids via $\eta^{2}$ coordination. RSC Advances, 8526-8530.

Baybaş, D., Güler, R., Güler, H., Ayçı, G.A,. 2010. Amidoksimlenmiş Ağ Yapılı Bir Polimerin (IPN) ${ }^{228} \mathrm{Ac}^{3+},{ }^{212} \mathrm{~Pb}^{2+},{ }^{212} \mathrm{Bi}^{3+},{ }^{208} \mathrm{Tl}^{+}$ ve $\mathrm{UO}_{2}{ }^{2+}$ İçin Adsorban Özelliklerinin İncelenmesi. C.Ü. Fen-Edebiyat Fakültesi, Fen Bilimleri Dergisi. 31, 43-54.

Bulut, A., Yuşan, S., Aytas S., Sert, S. (2018). The use of sea shell (Donax trunculus) powder to remove Sr(II) ions from aqueous solutions. Water Science \& Technology, 78, 87-836.

Can, H.K., Doğan, A.L., Rzaev, Z.M.O., Üner, A.H., Güner, A. (2006). Synthesis, characterization, and antitumor activity of poly(maleic anhydride-co-vinyl acetate-co-acrylic acid). Journal of Applied Polymer Science, 100, 3425-3432.

Chen, B., Wang, J., Kang, L., Mai, X., Zheng, N., Zhang, Q., Liang, J., Chen, D. (2017). Adsorption of uranium from uranium mine contaminated water usingphosphate rock apatite (PRA): Isotherm, kinetic and characterizationstudies. Colloids and Surfaces A: Physicochemical and Engineering Aspects, 520, 612-621.

Chen, M., Li, Z., Geng, Y., Zhao, H., He, S., Li, Q. (2018). Adsorption behavior of thorium on N,N,N',N'-tetraoctyldiglycolamid (TODGA) impregnated graphene aerogel. Talanta, 181, 311-317.

Das, S., Brown, S., Mayes, R. T.; Janke, C. J., Tsouris, C., Kuo, L. J.; Gill, G., Dai, S. (2016). Novel poly(imide dioxime) sorbents: Development and testing for enhanced extraction of uranium from natural seawater. Chemical Engineering Journal, 298, 125-135.

Gao, Q., Hu J., Li, R., Xing, Z., Xu, L., Wang, M., Guo, X., Wu, G. (2016). Radiation synthesis of a new amidoximated UHMWPE fibrous adsorbent with high adsorption selectivity for uranium over vanadium in simulated seawater. Radiation Physicsand Chemistry, 122, 1-8.

Gunathilake, C., Gorka, J., Dai, S., Jaroniec, M. (2015). Amidoxime-modified mesoporous silica for uranium adsorption under seawater condition. Journal of Materials Chemistry A, 3, 11650-11659.

Huang, L., Zhang, L., Hua, D.J. (2015). Thin metal nanostructures: synthesis, properties and applications. Radioanal Nuclear Chemistry, 305, 445-453.

Khalili, F., Al-Banna G. (2015). 'Adsorption of Uranium(VI) and Thorium(IV) by insolubilized humic acid from Ajloun soil-Jordan'. Journal of Environmental Radioactivity, 146, 16-26.

Kong, L., Zhu Y., Wang M., Li Z., et. al. (2016). Simultaneous reduction and adsorption for immobilization ofuranium from aqueous solution by nano-flake. Journal of Hazardous Materials, 320, 435-441. 
Kokosza, K., Balzarini, J., Piotrowska, D.G. (2013). Design, synthesis, antiviral and cytostatic evaluation of novel isoxazolidine nucleotide analogues with a carbamoyl linker. Bioorganic \& Medicinal Chemistry, 21, 1097-1108.

Liu, S., Yang, Y., Liu, T., Wu, W. (2017). Recovery of uranium(VI) from aqueous solution by 2-picolylamine functionalized poly(styrene-co-maleic anhydride) resin. Journal of Colloid and Interface Science, 497, 385-392.

Lu, X., He, S. N., Zhang, D. X., Reda, A. T., Liu, C., Feng, J., Yang, Z. (2016). Synthesis and characterization of amidoxime modified calix [8] arene for adsorption of $\mathrm{U}(\mathrm{VI})$ in low concentration uranium solutions. RSC. Advances, 6, 101087-101097.

Qadeer, R., Saleem, M. (1997). Adsorption $\mathrm{UO}_{2}{ }^{2+}$ ions on activated charcoal: pH effect. Adsorption Sceince and Technology, 15, 373376.

Pekel, N., Şahiner, N., Güven, O. (2000). Development of new chelating hydrogels based on N-vinyl imidazole and acrylonitrile. Radiation Physics and Chemistry, 59, 485-491.

Rahman-Sani, A., Bandegharaei, A.H., Hosseini, S.H., Kharghani, K., Zarei, H., Rastegar, A. (2015). Kinetic, equilibrium and thermodynamic studies on sorption of uranium and thorium from aqueous solutions by a selective impregnated resin containing carminic acid. Journal of Hazardous Materials, 286, 152-163.

Shen, J. N., Yu, J., Chu, Y. X., Zhou, Y., Chen, W. J. (2012). Preparation and Uranium Sorption Performance of Amidoximated Polyacrylonitrile/Organobentonite Nano Composite. Advanced Materials Research, 476-478.

Sorg, T.J. (1991). Radon, Radium and Uranium in Drinking Water. Removal of uranium from drinking water by conventional treatment methods, Cothern and Rebers (Eds) Lewis Publishers, Michigan. ISBN 0873712072. 173-191.

Stemper, J., Tuo, W., Mazario, E., Helal, A.S., Djurovic, A., Lion., C., C., Chahine, J.M., Maruel, F., Hemadi, M. (2018). Synthesis of bis(amidoxime)s and evaluation of their properties as uranyl-complexing agents. Tetrahedron, 74, 2641-2649.

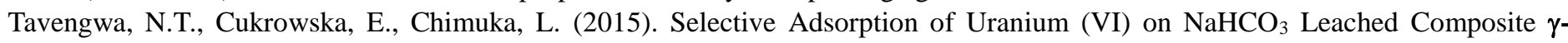
Methacryloxypropyltrimethoxysilane Coated Magnetic Ion-imprinted Polymers Prepared by Precipitation Polymerization. South Africa Journal. Chemistry, 68, 61-68.

Xu, C.; Wang, J.; Yang, T.; Xia, C.; Liu, X.; Ding, X. (2015). Adsorption of uranium by amidoximated chitosan-grafted polyacrylonitrile, using response surface methodology. Carbohydrate Polymers, 121, 79-85.

Wei, M. Liao, J.L. Liu, N. Zhang, D. Kang, H.J. Yang, Y.Y. Yong, Y. and Jin, J.N. (2007). Interaction between uranium and humic acid (I): adsorption behaviors of U(VI) in soil humic acids. Nuclear Science and Techniques, 18, 287-293.

Yi, Z., Yao, J., Kuang, Y., Chen, H., Wang, F., Xu, S. (2016). Uptake of hexavalent uranium from aqueous solutions using coconut husk activated carbon. Desalination and Water Treatment, 57, 1749-1755.

Zeng, J., Zhang, H., Sui, Y., Hu, Y., Ding, D., Wang, F., Xue, J., Wang, Y. (2017). New Amidoxime Based Material TMP-g-AO for Uranium Adsorption under Seawater Conditions. Industrial \& Engineering Chemistry Research, 1-42. 